\title{
Review of Matrix Metalloproteinases' Effect on the Hybrid Dentin Bond Layer Stability and Chlorhexidine Clinical Use to Prevent Bond Failure
}

\author{
Peter C. Moon ${ }^{1 * *}$, Jared Weaver ${ }^{2}$ and Carol N. Brooks ${ }^{1}$ \\ ${ }^{I}$ Department of General Practice, VCU School of Dentistry, Virginia Commonwealth University, Richmond, Va. USA \\ ${ }^{2}$ Private Practice, Huntsville, Utah, USA
}

\begin{abstract}
This review describes the relationship between dentin collagen hybrid bond layer degradation and the Matrix Metalloproteinases (MMPs) after their release by acid etch and rinse adhesives and self etching bonding adhesives that can reduce the bond stability over time. MMP-2, MMP- 8 and MMP-9 are indicated as the active proteases that breakdown the collagen fibrils in the hybrid bond layer. Phosphoric acid in the acid etch and rinse bonding process and acid primers in the self etch process are implicated in the release of these proteases and their activation by several non-collagen proteins also released from dentin by the etching. MMPs are released in saliva by salivary glands, by cells in the gingival crevices to crevicular fluid and by pulpal odontoblasts cells to the dentinal fluids. These sources may affect the hybrid layer also. Evidence of the bond strength deterioration over time and the ability of Chlorhexidine to prevent bond deterioration by inhibiting MMP action are discussed. Dentin Bonding procedure utilizing Chlorhexidine for different application times and concentrations are being developed. The application of $2 \%$ Chlorhexidine to the phosphoric acid etch surface after rinsing off the acid is the only procedure that has been clinically tested for a longer period of time and shown to prevent bond strength degradation so far. The adoption of this procedure is recommended as means of improving bond stability at this time.
\end{abstract}

Keywords: Matrix Metalloproteinases, Collagen, hybrid bond layer, bond strength, Chlorhexidine.

\section{INTRODUCTION}

Early dentin bonding agents were very prone to failure. As evident by many generations of dentin adhesives that have been developed over the years, perfection has yet to be achieved. Bonds still fail. Recent research has suggested that matrix metalloproteinases released from the dentin by acids during bonding may contribute to eventual bond failure. Reviews have explored the important roles matrix metalloproteinases (MMPs) play in general and dental health [1-3]. We will discuss these roles but focus on recent research utilizing chlorhexidine (CHX) which is a clinically relevant proteinase inhibitor. We will discuss the evidence that it can stabilize the dentin hybrid bond strength of bonded composite resin restorations to dentin and recommend procedures for use in dentin bonding.

\section{BACKGROUND ON MMPS}

Matrix Metallo Proteinases (MMPs) are a cell-derived proteolytic enzyme family with 26 identified members [1]. Specific enzymes of this family can function beneficially during tissue remodeling and during formation of the extra cellular matrix or the mineralization of dentin [4].

However, MMPs can act during inflammation to increase the adverse effects of cardiovascular disease [5], cancer metastasis [6], periodontal disease [7] and the carious process

*Address correspondence to this author at the Department of General Practice box 980566, VCU School of Dentistry, Virginia Commonwealth University, Richmond, Va. USA, 23298; Tel: -804-828-2977; Fax: -804-8283159; E-mail: pcmoon@vcu.edu
[8] by destruction of the collagen and other proteins of the extra cellular matrix. Normally, the protein cleavage activity of MMPs is balanced in time and spatially by cell secreted inhibitors called Tissue Inhibitors of Metalloproteinases (TIMPs). If the balance is disturbed inflammation, arthritis, cancer and heart problems become manifest [2].

The relationship of active MMPs to the carious process provides a background to recent research on the effects of MMPs on the dentin hybrid layer bond stability $[6,8]$. A variety of MMPs have been identified in the carious lesions including MMP-2 (gelatinase), MMP-8 (collagenase), MMP9 (gelatinase) and MMP-20 (enamelysin) [1,2]. The dentin protein matrix is composed of $90 \%$ collagen (primarily type I) and $10 \%$ non-collagen proteins. The collagen proteins can be clipped in to pieces by MMP- 8 and further degraded by MMP-2 and MMP-9 after acid demineralization of dentin in the carious lesion. These MMPs may be present in the saliva, pulp or sequestered in dentin to be released in the local environment during the caries destruction of dentin $[1,2,9]$. The MMPs are located throughout the dentin but appear to be located intensively along the enamel-dentin junction and in the predentin [10]. Increased MMPs presence along the dentin-enamel junction may contribute to the widening of caries along this junction as it progresses into the dentin.

These MMPs are secreted from connective tissue cells (fibroblasts, osteoblasts, and odontoblasts) as zymogens, a pro or inactive enzyme form, which does not cleave extra cellular proteins. The pro-MMPs are trapped or bound in the dentin during its formation [11]. They can be catalyzed to active enzymes after being released from the dentin by low- 
ering the $\mathrm{pH}$ to 4.5 or below as in carious lesions [2]. The pro-MMPs after release by the acid can be activated by interactions with specific extracellular matrix proteins also released from the dentin or present in saliva. They will remain active even if the $\mathrm{pH}$ is neutralized. The release and increased activation of MMPs can also occur during acid treatment of dentin powders with lactic and citric acids but phosphoric acid greatly decreased activation [12, 13]. For example, a $37 \%$ phosphoric acid gel decreased collagenolytic activity by $65 \%$ compared to the effect of no gel on mineralized dentin powder [13]. However, application of five etch and rinse dentin bonding acidic resins (Prime and Bond, Optibond Solo Plus, Excite, Single Bond and One Step) raised collagenolytic activities $45 \%$ to $260 \%$ over the activity of the control non treated dentin powder. In addition, self etching adhesive resin (acidic resins) created a 14 fold increase in MMP enzyme activity when applied to dentin powders [14]. These results suggest that organic acidic molecules play a particularly important role in activating pro MMPs to active proteinases. The lactic acid released by bacteria in a carious lesion has been implicated as an activator of pro MMPs that break down collagen matrix during the caries process [15]. This evidence suggests that organic acids released from plaque or present in the diet could contribute to weakening of the hybrid bond in time. Another possible source of MMP attack on the hybrid layer was found recently when self etching resins placed on prepared dentin produced secretion of MMPs from odontoblasts at the pulp dentin interface. These MMPs may gain access to the hybrid layer via the dentinal tubules [16].

Ten percent of the non-collagen proteins of the dentin matrix proteins consist of three proteins that can bind to specific MMPs. These binding proteins may activate the MMPs when they are released by the acid attack in caries or potentially during acid etching for bonding [2].

These activating proteins are part of the Small Integrin $\underline{B}$ inding Ligand $\underline{N}$-linked Glycoproteins (SIBLING) gene family [17]. The three binding proteins are Bone Sialoprotein (BSP), Osteopontin (OPN) and Dentin Matrix Protein1 (DMP1). The MMPs and binding proteins pair specifically together in the following groups for activation: MMP-2 with BSP, MMP-3 with OPN and MMP-9 with DMP1.

The activation of pro-MMPs to active forms is complex and dynamic for which several mechanisms have been suggested [18]. The N-terminus of the these MMP enzymes are thought to be folded over to block the active catalyst site so $\mathrm{Zn}$ or $\mathrm{Ca}$ ions can not bind to activate MMPs [19]. This Nterminus part of the molecule can be cleaved off the proMMP by another enzyme to form an active MMP that can bind $\mathrm{Zn}$ and $\mathrm{Ca}$ ions from the extra cellular environment [20].

Another mechanism that is similar to the SIBLING binding to activate MMPs is that of the binding of another molecule to an MMP which causes the N-terminus end to be displaced so that $\mathrm{Zn}$ or $\mathrm{Ca}$ binding site is no longer blocked [21]. A combination of these first two mechanisms may act in concert where another molecule binds to change the molecular configuration to partially activate the MMP or displace the $\mathrm{N}$-terminus allowing the reaction of water with the active site which enhances the removal of the $\mathrm{N}$-terminus by protease enzymes [22]. On the other hand, CHX is thought to chelate to the zinc or calcium ions on the active site to inhibit the MMPs that had been activated by a mechanisms such as those discussed [23]. If the concentration of zinc ions is high as can occur by release of this ion from zinc containing dental materials, the MMPs can be inhibited [24]. The additional zinc ions may bind to lower affinity sites on the MMPs changing its molecular configuration so it is no longer active or by zinc hydroxide bridge to block the active site $[25,26]$.

It is of particular interest that application of acid resins of dentin bonding agents after the activation is depleted by the phosphoric acid etchant in the etch and rinse bonding agents more than restores the MMP activity in the dentin. Furthermore, the more acidic the bonding resin, the higher the restored activity of the MMPs [13,14]. Also, the acidic self etching bonding resins restored activation of the MMPs of dentin powder when used in a manner simulating bonding to dentin. In addition, activated MMPs may find their way to the hybrid bond layer interface via microleakage or nanoleakage at bond gaps, from MMPs in saliva, crevicular fluid and via dental tubule fluid from the pulp over time [2, 27, 28].

\section{THE LINK BETWEEN MMPS AND DENTIN HYBRID BOND STABILITY}

With this background above, it is concluded that MMPs can be released by acids (inorganic and organic) and activated by SIBLING proteins and organic acids in the oral environment or in the bonding adhesives. If collagen fibrils are left exposed in the hybrid bond layer unprotected by resin, they can be degraded by the activated MMPs. The reports of nano leakage between the etch and rinse or self etch dentin bonding resins and dentin suggest fibril exposure occurs in clinical placement of resin bonded restorations [2931]. With time, bond degradation may show up as a loss of retention clinically or a decrease in bond strength with in vitro testing. A clinical review of different types of dentin bonding agents showed that for Class $\mathrm{V}$ composite restorations that the majority of bonding agents declined in retention by $20 \%$ in five years or less [32]. In addition, if the composite shrinkage stress is sufficient, an interfacial gap can form that may lead to tooth sensitivity and marginal staining. These problems may influence a dentist to replace a composite restoration. Replacement is more likely to occur if the dentist did not place the restoration and thus does not know its history [33]. Marginal chipping can also lead to partial or complete restoration replacement [34]. These causes of failure may be influenced by degradation in the bond strength with time.

Microtensile bond strength tests have been performed on clinically placed bonded composites that were orally aged in function and then extracted for orthodontic treatment and tested. Their bond tests demonstrated significant bond strength loss of $36 \%$ to $70 \%$ at one year and at fourteen months with different bonding agents $[35,36]$. Similar significant degradation in bond strength of $40 \%$ was measured for dentin bonded composite in extracted teeth, water aged in vitro, at a shorter time, 270 days [37]. The degradation of the hybrid bond layer was confirmed by electron transmission microscopy comparison of the hybrid layer for the standard etch and rinse only but not for those treated with $2 \%$ chlor- 


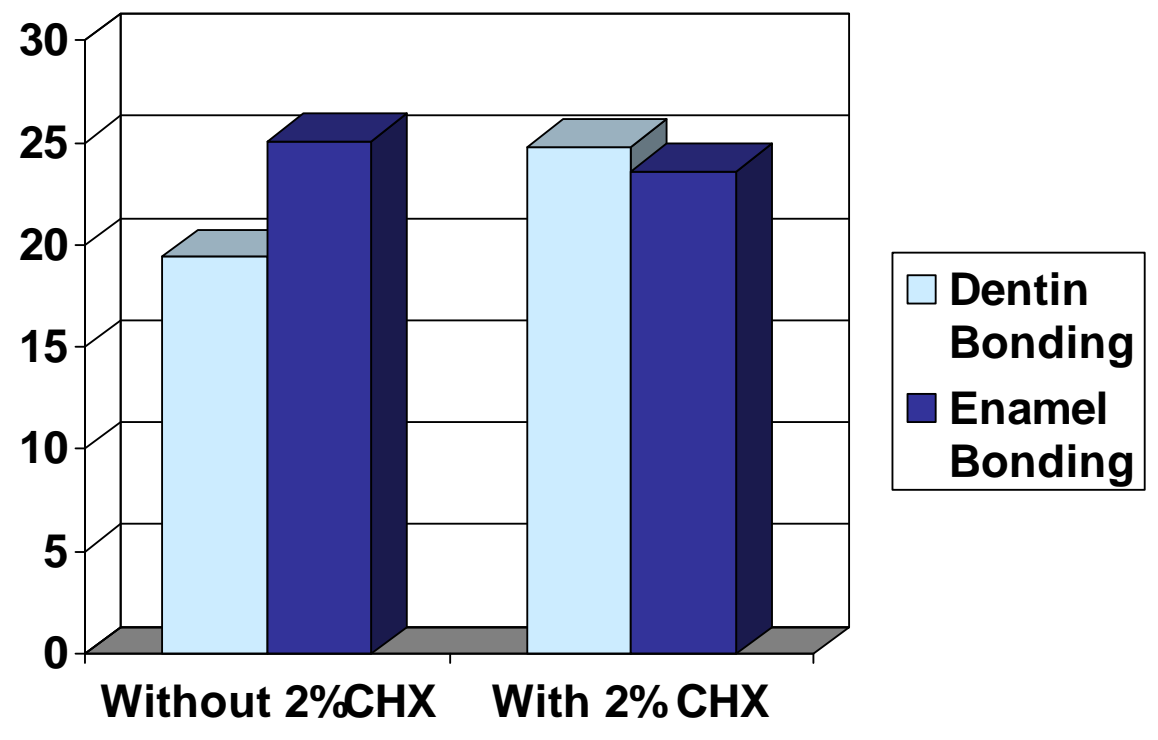

Fig. (1). Chart of shear bond strengths 24 hours after bonding of OptiBond Solo Plus to enamel and dentin with and without the application of $2 \%$ chlorhexidine to bond Filtek Z250 composite to extracted teeth.

hexidine $(\mathrm{CHX})$ after acid etching, water rinsing and drying before bond resin application [38].

Chlorhexidine had been used primarily as a disinfectant for cavity preparations and oral irrigation in dentistry. There have been reports which indicate that chlorhexidine application to the acid etched surfaces of enamel and dentin does not decrease bond strength in vitro of composite resin in the short term (24 hours) [39-46]. Also, the early bond strength to caries affected dentin in vitro is reported to be unchanged by application of $2 \%$ chlorhexidine after acid etching with phosphoric acid. The caries affected dentin produced similarly lower bond strengths with or without the application of chlorhexidine [47-49].

We initially measured an increase in shear bond strength of $24 \%$ with $2 \% \mathrm{CHX}$ applied to etch and rinse dentin after water rinsing [45]. The composite cylinder bond was formed against a recently extracted molar tooth $(n=10)$ whose dentin was prepared flat by a diamond saw, treated with and without $2 \%$ Chlorhexidine after acid etching. The bonding procedure to dentin used Scotch Bond (3M ESPE St. Paul, MN. USA) phosphoric acid etchant for $15 \mathrm{sec}$., rinsing $15 \mathrm{sec}$. and drying to moist dentin before applying the $2 \%$ Chlorhexidine (Consepsis, Ultradent Inc., South Jordan, UT. USA) for one minute with redrying to a moist dentin surface. Next, two coats of Optibond Bond Solo Plus were applied with $5 \mathrm{sec}-$ onds of air drying after each before being visible light cured (VLC) for twenty seconds to which a $2 \mathrm{~mm}$ high cylinder of Filtek Z250 (3M ESPE St. Paul, MN. USA) was placed using an Ultradent bonding jig. The Filtek Z250 was visible light cured (VLC) for forty seconds. The VLC were performed at $400 \mathrm{mw} / \mathrm{cm}^{2}$ with an Optilux Model VCL 401 curing light (Kerr Inc., Danbury Ct. USA). The average shearbond strength to dentin increased from 19.4 +/- 1.4 MPa for the control without chlorhexidine to $24.1+/-3.1 \mathrm{MPa}$ with $2 \%$ Chlorhexidine after storage in water at $100^{\circ} \mathrm{f}$ for 24 hours as listed in Fig. (1). Retesting this procedure but with 10 seconds of air pressure drying after application each layer raised the bond strength at 24 hours to $29.6+/-4.6 \mathrm{MPa}$ without $\mathrm{CHX}$ and to $30.0+/-4.1 \mathrm{MPa}$ with $\mathrm{CHX}$. We now use clinically $2 \%$ Chlorhexidine with OptiBond Solo Plus for bonded direct composite restorations as of the Fall of 2007 in Virginia Commonwealth University Dental School Clinic. We started using Optibond Solo Plus in 2005 as it was available in unidose which we judged from experience would make student bonding procedures more effective and efficient.

A variety of etch and rinse dentin bonding resins have been tested with chlorhexidine without reporting a short term detrimental affect on bond strength [39-46]. Other bonding materials and procedures may work equally well with chlorhexidine. It is advisable to test at least their 24 hour bond strength in vitro to determine $\mathrm{CHX}$ does no harm immediately and to follow with extended time tests to show their longer term benefit as we are in the process of doing. It is expected that many bonding agents, procedure modifications and MMP inhibitors will be tested in the search for more efficient ways to stabilize the hybrid bond against MMPs.

Of the several variations in procedures so far reported, one showed that the 24 hour bond strength of a self etch bonding agent was decreased by approximately $20 \%$ if the $2 \%$ CHX was applied to the dentin before self etch resin. But it was not affected by the addition of up to $1 \% \mathrm{CHX}$ when added to Clearfil SE Bond (Kuraray America Inc., New York, NY. 10022) resin [50,51]. Further research on the long term effect of adding $\mathrm{CHX}$ to Clearfil SE bonding resin at concentrations of $0.1 \%, 0.5 \%$ or $1 \%$ proved at one year in vitro to protect the bond against degradation but $0.05 \%$ did not [52]. It should be recognized that MMPs from saliva, odontoblasts via dentinal tubules and from crevicular fluid are not present during in vitro bond conditioning in water baths. This suggests that there may be a need for a higher CHX concentration in vivo than in vitro to prevent bond degradation clinically. However, one product, Hemaseal \& Cide with 4\% CHX, (Advantage Dental Products Inc., Lake Orion, MI. 48361) that is described as a desensitizer and disinfectant agent suggests it can be used for self-etch as 
well as with etch and rinse adhesive systems. Research using chlorhexidine reported by Christensen Research Associates as a disinfectant did not weaken the 24 hour bond for five dentin bonding agents [53]. Of those tested, two were selfetch and three were etch and rinse systems. Molecularly, chlorhexidine can be chemisorbed on the hydroxyapatite of the tooth or react as an ion to form an insoluble compound with phosphate ions in plaque, saliva and hydroxyapatite. It may be released later without apparently interfering with bonding to enamel or dentin at the concentrations tested [54].

The clinical application of $2 \%$ chlorhexidine for one minute to the etched dentin after rinsing off the acid and before applying the dentin bonding primer and resin is able to stop significant in vivo degradation of bond strength from MMPs for at least 14 months [36-38]. Chlorhexidine was applied after rinsing off the acid with water and air drying the dentin to just a moist surface. This method is the only one proven clinically, is easy to adopted and will likely be first to gain wider acceptance initially. However research is expected to develop simpler and more efficient methods of applying CHX or other MMP inhibitors. For example, recently it has been demonstrated for six months in vitro that addition of $2 \%$ CHX to a conventional $37 \%$ phosphoric acid prevented degradation of the bond strength of an etch and rinse bonding system [55]. The influence of concentration and application time of CHX have been evaluated to show that times less than one minute and concentrations less than $2 \%$ may prevent degradation in vitro [56]. These results are yet to be verified in vivo. For resins that might be used in a self etch bonding resin systems, research has shown that CHX influences the degree of cure and the elastic modulus on curing. These results suggest that the success of adding CHX to self etch systems to prevent hybrid bond degradation will vary with the resin used in the commercial products [57]. In vitro application of concentrations of greater than $0.12 \%$ CHX to dentine before applying the primer is contraindicated as it can reduce the 24 hour bond strength [58]. The use of $0.12 \%$ CHX mouth wash to rub on the preparation might seem to be the most immediate way to treat self etch dentin bonds.

More research is needed to show that treatment does not weaken the 24 hour bond and works for a long time in vitro and in vivo for the variety of self etching agents available. Moreover, in vitro tests simulating pulp pressure and thermo-mechanical action exerted on the self etch adhesive dentin bond to which the CHX was applied prior to the adhesive showed loss of bond strength at 6 months. But the loss was much less with the $2 \% \mathrm{CHX}$ compared to $0.2 \% \mathrm{CHX}$ and no CHX [59].

It is hoped that knowledge to improve bonding procedures for stability of self etch systems will evolve from further research so bond stability of these products will improve.

\section{RECOMMENDED CLINICAL APPLICATION PRO- CEDURE}

With the best in vitro and limited clinical research evidence verifying no immediate bond weakening and improve long term stability with the use of etch and rinse dentin bonding adhesives, we suggest the clinical use with $2 \%$ chlorhexidine at this point of time. The reported in vivo test were performed with Single Bond (3M) using 2\% Chlorhexidine digluconate solution (CHX) by Proderma, Peracicaba SP, Brazil.

Based on convenience and what was available at our clinics, we selected the $2 \%$ chlorhexidine solution, Consepsis (Ultradent, Inc., South Jordan, UT 84095), applied it for one minute after etching with $37 \%$ phosphoric acid for 15 seconds, water rinsing thoroughly and drying to moist surface before applying CHX. The CHX treated surface is again dried to a moist surface followed by the resin application of adhesive resin like Optibond Solo Plus (Kerr U.S.A., Orange, CA 92867) which we use. In addition, to enhance the bond strength, we recommend at least two separate coats of the bonding agent resins applied without pooling of the resins in the prep [29]. Also, air pressure drying is required to evaporate the solvent out of the bonding resins for $10 \mathrm{sec}-$ onds between coats and after the last coat to insure thorough light curing. Better solvent evaporation increases the degree of cure and prevents excess water absorption by water displacement of the remaining solvent. This increases bond strength, decreases nano leakage, hydrolysis of the resin and MMPs attack on the collagen of the hybrid layer with time [60]. These procedures are design to minimize sensitivity, marginal staining, or chipping and improve retention of direct bonded composite restorations.

The work was partly supported by an AD Williams Foundation Student Fellowship for Dr. Weaver.

\section{REFERENCES}

[1] Hanna AR, Pereira JC, Granjeiro JM, Tjaderhane L. The role of matrix metalloproteinases in the oral environment. Acta Odont Scand 2007; 65: 1-13.

[2] Chaussain-Miller C, Fioretti G, Goldberg M, Menashi S. The role of matrix metalloproteinases (MMPs) in human caries. J Dent Res 2006; 85: 22-32.

[3] Corbitt CA, Lin J, Lindsey ML. Mechanisms to inhibit matrix metalloproteinase activity: where are we in development of clinically relevant inhibitors? Rec Pat on Anti-Cancer Drugs 2007; 21: 35-42.

[4] Fanchon S, Bourd K, Septier D, et al. Involvement of matrix metalloproteinases in the onset of dentin mineralization. Eur J Oral Sci 2007; 112: 171-6.

[5] Kukacka J, Prusa R, Kotaska K, Pelouch V. Matrix metalloproteinases and their function in myocardium. Biomed Papers 2005; 149: 225-36.

[6] Nemeth JA, Yousif R, Herzog M, et al. Matrix metalloproteinase activity, bone turnover, and tumor proliferation in prostate cancer bone metastasis. J Nat Cancer Inst 2002; 94: 17-25.

[7] Liu KZ, Hynes A, Man A, Alsagheer A, Singer DL, Scott DA. Increased local matrix metalloproteinase- 8 expression in the periodontal connective tissues of smokers with periodontal disease. Biochim et Biophys Acta Mol Basis of Dis 2006; 1762: 775-80.

[8] Sulkala M, Wahgren J, Lamas M, et al. The effects of mmp inhibitors on human salivary mmp activity and caries progression in rats. J Dent Res 2001; 80: 1545-9.

[9] Dayan D, Binderman I, Mechanic GL. A preliminary study of activation of collagenase in carious human dentine matrix. Arch Oral Biol 1983; 28: 185-7.

[10] Boushell LW, Kaku M, Mochida Y, Bagnell R, Yamauchi M. Immunohistochemical localization of matrix metalloproteinase-2 in human coronal dentin. Arch Oral Biol 2008; 53(2): 109-16.

[11] Mazzoni A, Mannello F, Tay FR, et al. Zymographic analysis and characterization of MMP-2 and -9 forms in human sound dentin. J Dent Res 2007; 86(5): 436-40. 
[12] Pashley DH, Tay FR, Yiu C, et al. Collagen degradation by hostderived enzymes during aging. J Dent Res 2004; 83(3): 216-21.

[13] Mazzoni A, Pashley DH, Nishitani Y, et al. Reactivation of inactivated endogenous proteolytic activities in phosphoric acid- etched dentin by etch - and - rinse adhesives. Biomaterials 2006; 27 : 4470-6.

[14] Tay FR, Pashley DH, Loushine RJ, Weller RN, Montecelli F, Osotio R. Self-etching adhesives increase collagenolytic activity in radicular dentin. JOE 2006; 32(9): 862-8.

[15] Chaussain-Miller C, Fioretti F, Goldberg M, Menashi S. The role of matrix metalloproteinases (MMPs) in human caries. J Dent Res 2006; 85(1): 22-32.

[16] Lehmann N, Debret A, Romeas A, et al. Self etching increases matrix metalloproteinase expression in dentin-pulp complex. J Dent Res 2009; 88(1): 77-82.

[17] Fedarko NS, Jain A, Karadag A, Fisher LW. Three small integren binding Ligand N- linked glycoproteins (SIBLINGs) bind and activate specific matrix metalloproteinases. FASER J 2004; 18: 734-6.

[18] Sagit I, Rosenblum G, Meroueh SO, Toth M, Fisher R, Mobashery S. Functional protein motion during activation of matrix metalloproteinase zymogen. 237 ${ }^{\text {th }}$ ACS meeting abstract 2009; Phys-178.

[19] Kotra LP, Cross JB, Shimura Y, Fridman R, Schlegel HB, Mobashery S. Insight into the complex and dynamic process of activation of matrix metalloproteinases. J Am Chem Soc 2001; 123(13): 3108-13.

[20] Nagase H, Suzuki K, Morodomi T, Enghild JJ, Salvesen G. Activation mechanisms of the precursors of matrix metalloproteinases 1, 2 and 3. Matrix (Stuttgart, Germany) Suppl 1992; 1: 237-44.

[21] Jain A, Karadag A, Fisher LW, Fedarko NS. Structural requirements for bone sialoprotein binding and modulation of matrix metalloproteinase-2. Biochemistry 2008; 47(38): 10162-70.

[22] Kotra LP, cross JB, Shimura Y, Fridman R, Schlegel HB, Mobashery $\mathrm{S}$. Insight into the complex and dynamic process of activation of matrix metalloproteinases. J Am Chem Soc 2001; 123: 3108-13.

[23] Gendron R, Grenier D, Sorsa T, Mayrand D. Inhibition of the activities of matrix metalloproteinases 2,8 , and 9 by chlorhexidine. Clin Diagn Lab Immunol 1999; 6(3): 437-9.

[24] Santos MCLG, De Souza AP, Grlach RF, TREVilatto PC, ScarelCaminaga RM, Line SRP. Inhibition of human pulpal gelatinases (MMP-2 and MMP-9) by zinc oxide cements. J Oral Rehab 2004; 31: 660-4.

[25] de Souza AP, Gerlach RF, Line SRP. Inhibition of human gingival gelatinases (MMP-2 and MMP-9) by metal salts. Dent Mater 2000; 16: $103-8$.

[26] Larsen KS, Auld DS. Characterization of an inhibitory binding site in carboxypeptidase A. Biochemistry 1991; 30: 2613-8.

[27] Ingman T, Tervahartiala T, Ding Y, et al. Matrix metalloproteinases and their inhibitors in gingival crevicular fluid and saliva of periodontitis patients. J Clin Periodontol 1996; 23(12): 1127-32.

[28] Palosaarl H, Pennington CJ, Larmas M, Edwards DR, Tjaderhane L, Salo T. Expression profile of matrix metalloproteinases (MMPs) and tissue inhibitors of MMPs in human odontoblasts and pulp tissue. Eur J Oral Sci 2003; 111: 117-27.

[29] Hashimoto M, Sano H, Yoshida E, et al. Effects of multiple adhesive coatings on dentin bonding. Operat Dent 2004; 29(4): 416-23.

[30] Pioch T, Staehle HJ, Duschner H, Garcia-Godoy F. Nanoleakage at the composite- dentin interface: a review. Am J Dent 2001; 14(4): 252-8.

[31] Zhao S, Chen J, Zhang B, Wu W. Nanoleakage at composite-dentin interface of self- etching adhesives. Kouqiang Yixue 2006; 26(1): 22-4.

[32] Peumans M, Kanumilli P, De Munck J, Van Landuyt K, Lambrects P, Van Meerbeek B. Clinical effectiveness of contemporary adhesives: a systematic review of current clinical trials. Dental Mater 2005; 21 : 864-81.

[33] Bogacki RE, Hunt R J, del Aguila M, Smith WR. Survival analysis of posterior restorations using an insurance claims database. Operat Dent 2002; 27(5): 488-92.

[34] Peumans M, Van Meerbeek B, Lambrechts P, Vanherle G. The 5year clinical performance of direct composite additions to correct tooth form and position II marginal qualities. BIOMAT Clin oral investigat $1997 ; 1(1): 19-26$.
[35] Koshiro $\mathrm{K}$, Inoue S, Tanaka $\mathrm{T}$, et al. In vivo degradation of resindentin bonds produced by a self-etch vs. a total-etch adhesive system. Eur J Oral Sci 2004; 112(4): 368-75.

[36] Carrilho MRO, Geraldeli S, Tay F, et al. In vivo preservation of the hybrid layer by chlorhexidine. J Dent Res 2007; 86(6): 529-33.

[37] Breschi L, Cammelli F, Visintini E, et al. Chlorhexidine affects long-term microtensile bond strength for etched-and-rinse adhesives. IADR $85^{\mathrm{t}}$ General Session 2007; Abstract \# 0837.

[38] Hebling J, Pashley DH, Tjaderhane L, Tay FR. Chlorhexidine arrests subclinical degradation of dentin hybrid layers in vivo. $\mathrm{J}$ Dent Res 2005; 84(8): 741-6.

[39] Perdigo J, Denehy GE, Swift EJ. Effects of chlorhexidine on dentin surfaces and bond strength. Am J Dent 1994; 7: 1-84.

[40] Meiers JC, Shook LW. Effect of disinfectants on the bond strength of composite to dentin. Am J Dent 1996; 9: 1-14.

[41] Damon PL, Bishara SE, Olsen ME, Jakobsen JR. Bond strength following the application of chlorhexidine on etched enamel. Ang Orthodont 1997; 67: 167-72.

[42] de Sousa da Silva VR, Alves Jr I. Bond strength to primary tooth dentin following disinfection with a chlorhexidine solution: an in vitro study. Ped Dent 2003; 25: 49-52.

[43] de Castro FLA, de Andrade MF, Duarte Jr SLL, Vaz LG, Ahid FJM. Effect of $2 \%$ chlorhexidine on microtensile bond strength to dentin. J Adhes Dent 1992; 5:129-38.

[44] Can SE, Fatma K, Berna T, Mubin S, Turgut S. In vitro effect of cavity disinfectants on bond strength of dentin bonding systems. Quintessence Int 2004; 35: 56-60.

[45] Moon PC, Weaver J, Brooks CN. Effect of $2 \%$ chlorhexidine Consepsis application on composite bond strength to enamel and dentin. IADR 2009; Abstract \# 466.

[46] Pappas M, Burns DB, Moon PC, Coffey JP. Influence of a 3-step tooth disinfection procedure on dentin bond strength. J Prosthet Dent 2005; 93(6): 545-50.

[47] Erhardt MCG, Osorio R, Toledano M. Dentin treatment with MMPs inhibitors does not alter bond strengths to caries-affected dentin. J Dent 2008; 36(12):1068-73.

[48] Komori PCP, Pashley DH, Tjaderhane L, et al. Effect of $2 \%$ chlorhexidine digluconate on the bond strength to normal versus cariesaffected dentin. Operat Dent 2009; 34(2): 157-65.

[49] Ersin NK, Candan U, Aykut A, Eronat C, Belli S. No adverse effect to bonding following caries disinfection with chlorhexidine. J Dent Child 2009; 76(1): 20-7.

[50] Ercan E, Erdemir A, Zorba YO, et al. Effect of different cavity disinfectants on shear bond strength of composite resin to dentin. J Adhes Dent 2009; 11(5): 343-6.

[51] Tan JG, Zhou JF. Effect of chlorhexidine on bond strength of selfetching adhesive. IADR Abstract 2008; \#0357.

[52] Zhou J, Tan J, Chen L, Li D, TanY. The incorporation of chlorhexidine in a two - step self - etching adhesive preserves dentin bond in vitro. J Dent 2009; 37(10): 807-12.

[53] Christensen G. Desensitizers used with restorative procedures first look. Christ Res Associate Newslett 2002; 26(8): 1-3.

[54] Misra DN. Interaction of digluconate with and adsorption on hydroxyapatite. J Biomed Mat Res 1994; 28(11): 1375-81.

[55] Stanislawczuk R, Amaral RC, Zander-Grande C, Gagler D, Reis A, Loguercio AD. Chlorhexidine acid conditioner preserves the longevity of resin-dentin bonds. Operat Dent 2009; 34(4): 481-90.

[56] Loguercio AD, Stanislawzcuk R, Polli LG, Costa JA, Michel MD, Reis A. Influence of chlorhexidine digluconate concentration and application time on resin bond strength durability. Eur J Oral Sci 2009; 117: 587-96.

[57] Cadenaro M, Pashley DH, Machesi G, et al. Influence of chlorhexidine on the degree of conversion and e- modulus of experimental adhesive blends. Dent Mater 2009; 25: 1269-74.

[58] de Campos EA, Correr GM, Leonardi DP, Pizzatto E, Morais EC. Influence of chlorhexidine concentration on the microtensile bond strength of contemporary adhesive systems. Braz Oral Res 2009; 23(3): 340-5

[59] Campos EA, Correr GM, Leonardi DP, Barato-Fiho F, Gonzaga CC, Zielak JC. Chlorhexidine diminishes the loss of bond strength 
overtime under simulated pulpal pressure and thermo-mechanical stressing. J Dent 2009; 37: 108-14.
[60] Hashimoto M, Tay FR, Svizero NR, et al. The effects of common errors on sealing ability of total-etch adhesives. Dent Mater 2006; 22(6): 560-8.

Received: September 28, 2009

Revised: March 09, 2010

Accepted: March 09, 2010

(C) Moon et al.; Licensee Bentham Open.

This is an open access article licensed under the terms of the Creative Commons Attribution Non-Commercial License (http://creativecommons.org/licenses/by-nc/3.0/) which permits unrestricted, non-commercial use, distribution and reproduction in any medium, provided the work is properly cited. 